\title{
The role of Rhodotorula mucilaginosa in selected biological process of wild fish
}

\author{
Elżbieta Bogusławska-Wąs • Alicja Dłubala • \\ Maria Laskowska
}

Received: 12 June 2018 / Accepted: 22 November 2018 /Published online: 5 December 2018

(C) The Author(s) 2018

\begin{abstract}
Defense mechanisms of fish are investigated in many aspects. One of the most interesting systems is that based on non-specific immune factors whose mechanisms of biocontrol have evolved in complex processes of microbiological co-existence. The wild fish devoid of probiotic stimulation have developed their own system to control the biosynthesis of immunostimulating compounds based on commensal microflora. Results of this study demonstrated the gastrointestinal tract (GI) of wild fish (Abramis brama, Rutilus rutilus, Perca fluviatilis) was colonized by permanently residing strains of Rhodotorula mucilaginosa. The genetic profile of the tested strains (PCR-random amplification of polymorphic DNA) indicated their affinity only to the GI of the analyzed fish. The capability for biosynthesis of $\beta$-carotene, torulene, torularhodin, and exopolysaccharides (EPS) under conditions of fish gastrointestinal tract was found to be a strain-specific trait. Rhodotorula spp. interactions with fish should be considered as a mechanism of symbiotic relations based on the stimulation of nonspecific mechanisms of fish immunoprotection and antioxidative properties of yeast.
\end{abstract}

Keywords Yeasts $\cdot$ Rhodotorula $\cdot$ Fish $\cdot$ EPS . Carotenoid pigments

E. Bogusławska-Wąs $(\bowtie) \cdot$ A. Dłubała $\cdot$ M. Laskowska Department of Applied Microbiology and Biotechnology, Faculty of Food Science and Fisheries, West Pomeranian University of Technology, Papieza Pawla VI 3, 71-450 Szczecin, Poland e-mail: eboguslawska@zut.edu.pl

\section{Introduction}

The knowledge on the ecological role of microflora of wild fish gastrointestinal tract, especially that associated with yeast prevalence, is still insufficient. An important study area includes identification of the natural composition of this microflora, as the co-relationships within it may allow determining the real role of yeast in vital processes of fish. The functionality of unicellular fungi does not change in time on condition that they represent an element of permanent microbiota. In most cases, their counts do not exceed $2.0-5.0 \%$ of the total population of microorganisms isolated from fish. In the case of healthy and cultured fish, yeast prevalence is mainly discussed as closely related to the mechanisms of immunostimulation and to the process of gastrointestinal tract maturation (He et al. 2011; Gopalakannan and Arul 2010; Meena et al. 2013). As yeast represent a valuable source of enzymes, vitamins, amino acids, and oligosaccharides (Lokesh et al. 2012), in the opinion of some scientists, they are better growth promoters than the probiotic bacteria are (Caruffo et al. 2015). Their antimicrobiological properties are also increasingly often emphasized (Hatoum et al. 2012). Investigations on the health-promoting effects of yeast concern mainly Saccharomyces cerevisiae, Debaryomyces hansenii, and Phaffia rhodozyma (Caruffo et al. 2015; Irianto and Austin 2002) have been mainly conducted with cultured fish, while the aspect of the ecological role of yeast in wild fish seems to be completely neglected.

The prevalence of yeast in the biosphere is not random. It is subject to biological regulation by communities producing them and depends on preferences for the 
colonized site (Boguslawska-Was 2010). A thesis was adopted in this study that yeasts - as opportunistic pathogens - do not pose any direct health risk and influence the regulation of fish defense mechanisms. It was assumed that metabolites of physiologically active yeast may be used by fish in multiple biological processes. The functionality of unicellular fungi does not change if that they represent an element of permanent microbiota and that homeostasis is maintained between microorganisms, which ensures keeping the safety rigor. Hence, in this work, we have focused only on these yeast strains whose prevalence was not prevented by conditions of the gastrointestinal tract environment.

\section{Materials and methods}

Sample collection and isolation of yeast Samples of water and three fish species, bream (Abramis brama Linnaeus, 1758), roach (Rutilus rutilus Linnaeus, 1758), and perch (Perca fluviatilis Linnaeus, 1758), were collected from March to November from three zones of Odra River Estuary. The above fish species were selected for the study based on traits of their gastrointestinal tract, feeding area, and place in the trophic chain. Their gastrointestinal tract (GI) and epidermal mucus (EM) were examined. In total, 120 fish and 30 water samples were analyzed in the study. Microbiological analyses were carried out on the sampling day. The GI of fish was prepared aseptically, intestinal digesta was removed, and then the tract was flushed and homogenized in physiological saline solution $(0.9 \% \mathrm{v} /$ $w, \mathrm{pH}$ 7.0). Mycological analyses of GI and EM were conducted on the SDA culture medium (Sabouraud dextrose agar $0.5 \%$-yeast extract, 2.0\%-glucose, $2.0 \%$-agar; $\mathrm{pH} 4.5$; Scharlau) with the addition of chloramphenicol (Interforum Pharma). Incubation was conducted at a temperature of $22^{\circ} \mathrm{C}$ for $48-72 \mathrm{~h}$. In turn, microbiological analyses of water samples were conducted using a membrane inoculation technique (Sartorius) under culture conditions as described above.

Biochemical and genetic characterization of the isolates Strains were identified based on their macroscopic and biochemical traits using the API 20C AUX system (bioMerieux). Species identity of selected strains (Rhodotorula mucilaginosa and Rhodotorula glutinis) was confirmed with the PCR method, accordingly to White et al. (1990). Cultures were incubated on the YEPD medium (1.0\% yeast extract, $2.0 \%$ - peptone, $2.0 \%$-glucose; Scharlau) at $22{ }^{\circ} \mathrm{C}$ for $24 \mathrm{~h}$. Genetic differentiation analysis was carried out with the random amplified polymorphic DNA method (RAPD-PCR). Genomic DNA was isolated following the protocol of the QIAamp DNA Mini Kit (Qiagen) using lyticase (Sigma-Aldrich). Strains of $R h$. mucilaginosa were differentiated with the following combination of starter cultures: 1254: CCg CAg CCA A and 1290: gTg gAT gCg A, whereas Rh. glutinis intraspecies differentiation was conducted with ERIK2: AAgTAAgTgACTggggTgAgCg (Bogusławska-Wąs 2010). The RAPD-PCR reaction was conducted in $25 \mu \mathrm{L}$ of the reaction mixture containing the following: $500 \mathrm{mM} \mathrm{KCl}, 100 \mathrm{mM}$ Tris- $\mathrm{HCl}\left(\mathrm{pH} 8.3\right.$ at $\left.25^{\circ} \mathrm{C}\right)$, $1.25 \mathrm{mM} \mathrm{MgCl}_{2}, 0.3 \mathrm{mM} \mathrm{dNTP}, 20 \mathrm{pmol} / \mu \mathrm{L}$ of each starter, $1 \mathrm{U}$ Taq DNA polymerase (Eppendorf), and 20 ng DNA template. The thermal profile used in the reaction consisted of 42 cycles, including $60 \mathrm{~s} / 94{ }^{\circ} \mathrm{C}$, $60 \mathrm{~s} / 36{ }^{\circ} \mathrm{C}$, and $60 \mathrm{~s} / 72{ }^{\circ} \mathrm{C}$. Amplification products were separated electrophoretically in $2.0 \%$ agarose gel (Prona Agarose Plus) with ethidium bromide $(0.5 \mu \mathrm{L} /$ $\mathrm{mL}$ ) (Bio-Rad, USA). Results of the electrophoretic separation were visualized in UV rays in a Gel Doc apparatus (Bio-Rad). Strain affinity degree was determined based on cluster analysis of the obtained amplification profiles (RAPD) with the unweighted pair group method with arithmetic mean (UPGMA) method in Bio-Gene software (Vilber Lourmat), with Dice coefficient of $3.0 \%$.

Microbial adherence Adherence of yeast strains was determined with the method of tetrazolium salt reduction (XTT; Sigma-Aldrich) accordingly to Jin et al. (2004). The experiment was conducted on 96-well titration plates (Sarstedt). Before being used, the plates were coated with $3 \%$ BSA $(100 \mu \mathrm{L} /$ well $)$ and left overnight at a temp. of $4{ }^{\circ} \mathrm{C}$. Next, the excess of bovine serum albumin was decanted, and the plates were doublerinsed with HEPES ( $\mathrm{pH}$ 7.0). The suspension of yeast strains $(100 \mu \mathrm{L})$ was introduced to wells and incubated at a temp. of $22^{\circ} \mathrm{C}$. To determine cell adherence degree (after 2, 6, 12, 24, and $48 \mathrm{~h}$ of incubation), the excess of culture was removed and the wells were double-rinsed with PBS. Afterwards, $100 \mu \mathrm{L}$ of the reaction mixture containing $1580 \mu \mathrm{L}$ PBS, $200 \mu \mathrm{L}$ XTT, and $20 \mu \mathrm{L}$ menadione (2-methyl-1,4-naphthoquinone; Sigma-Aldrich) was added accordingly to modified method of Ramage et al. (2001). The plates were incubated at 
$22^{\circ} \mathrm{C} / 2 \mathrm{~h}$, and then absorbance of the supernatant was measured at $\lambda=490 \mathrm{~nm}$ (Antachopoulos et al. 2006). Measurements were made with the Elx808 reader (BioTek Instruments) (Balcazar et al. 2008).

Cell growth and EPS production kinetics Mineral medium (SM) with pH 5.6 and the following composition was used to culture the test strains: $0.1 \%$ yeast extract, $0.2 \%\left(\mathrm{NH}_{4}\right)_{2} \mathrm{SO}_{4}, 0.1 \% \mathrm{KH}_{2} \mathrm{PO}_{4}, 0.05 \% \mathrm{MgSO}_{4}$, $0.01 \% \mathrm{CaCl}_{2}, 0.01 \% \mathrm{NaCl}$, and $5 \%$ sucrose (Ghada et al. 2012). Inoculum (5.0\% of total medium volume) consisted of $48 \mathrm{~h}$ yeast cultures prepared as above. The cultures were shaken $(200 \mathrm{rpm})$ at a temp. of $22{ }^{\circ} \mathrm{C}$ for $72 \mathrm{~h}$. Changes in cell counts were monitored by OD measurements at $\lambda=550 \mathrm{~nm}$ (NanoDrop ND-1000). The concentration of exopolysaccharides was determined with the ethanol precipitation method (Pavlova et al. 2005). A 50-mL sample was collected from the cultures and centrifuged in extraction flasks $(6000 \times \mathrm{g} /$ $30 \mathrm{~min}$ ). Supernatant was collected, and $96 \%$ ethanol was added (at 1:2 ratio). To obtain the precipitate, the samples were stored at $4{ }^{\circ} \mathrm{C}$ for $24 \mathrm{~h}$, and then centrifuged $(6000 \times \mathrm{g} / 10 \mathrm{~min})$. The resultant precipitate was rinsed with ethanol, centrifuged again, and dried until dry weight has been reached. Results obtained were used to calculate the specific production coefficient $\left(Y_{p / x}\right)$, accordingly to the following formula:

$Y_{p / x}=P / x$

where $P$-maximum exopolysaccharide concentration and $x$-yield of dry biomass.

Carotenoid pigments Biosynthesis of carotenoid compounds was determined in $72 \mathrm{~h}$ cultures which were incubated in the SM medium at a temp. of $22{ }^{\circ} \mathrm{C}$ and shaken at $200 \mathrm{rpm}$. Culture sample $(10 \mathrm{~mL})$ was then centrifuged $(6000 \times g / 10 \mathrm{~min})$. The resultant precipitate was double-rinsed with distilled water and centrifuged again. Afterwards, DMSO $\left(5 \mathrm{~mL}\right.$ at $\left.55^{\circ} \mathrm{C}\right)$ was added and the sample was vortexed $(60 \mathrm{~s})$. Next, hexadecane and $20 \% \mathrm{NaCl}$ were added in series $(0.5 \mathrm{~mL})$ (Stachowiak 2012). Absorbance of total carotenoids was measured with a UV-VIS spectrophotometer at $=490 \mathrm{~nm}$ (Cheng and Yang 2016). In the case of torulene and $\beta$-carotene, measurements were carried out at $\lambda=485 \mathrm{~nm}$ and $\lambda=450 \mathrm{~nm}$, respectively. The total content of carotenoids was calculated acc. to Maldonade et al. (2012) assuming the absorbance coefficient of $A_{1 \mathrm{~cm}}^{\%}=3240$ and expressed in micrograms per gram of dry matter.

\section{Results}

Differentiation of yeasts Mean counts of yeast isolated from water samples did not indicate any significant $(p>0.05)$ differences between seasons of the year and did not exceed $2.4 \log$ cfu $100 \mathrm{~mL}^{-1}$. In the case of fish mycocenoses, the level of GI colonization by unicellular fungi was comparable. The numbers of fungi determined for all fish species ranged from 2.44 to $2.94 \log \mathrm{cfu} \mathrm{g}^{-1}$. The significance of differences was not confirmed in any case $(p<0.05)$. In contrast, the number of yeast isolated from EM of all fish in the summer season was statistically lower (2.24-2.63 log) than in the spring and autumn seasons (3.55-4.43 log and 3.68-4.51 log, respectively). Results of these analyses are presented in Table 1.

Collection of samples and mycological analyses Of the 22 species of unicellular fungi isolated from fish catching sites, 10 were also detected in the ichthyofauna. Repeatedly isolated from all analyzed habitats were representatives of the following genera from the Basidiomycetes classes: Cryptococcus (Cr. uniguttulatus) and Rhodotorula (Rh. glutinis and Rh. mucilaginosa). The quantitative and qualitative analyses showed $R h$. mucilaginosa to predominate in the mycocenotic structure. Its contribution in the total number of yeast isolated from EM was determined at $19.5 \%$ in bream, $23.1 \%$ in roach, and $19.05 \%$ in perch. In turn, the contribution of Rhodotorula spp. in GI samples was at $20.0 \%, 17.9 \%$, and $41.7 \%$, respectively (Table 2).

Genetic diversity of Rh. mucilaginosa Yeast strains permanently isolated and predominating in the species structure of all analyzed habitats were subjected to interspecies typing with the RAPD-PCR method. Three non-affiliated genetic lines were distinguished based on the genetic patterns of $R h$. mucilaginosa $(S<50 \%$ at Dice $3 \%$ ), within which genotypes of strains with close affinity were distinguished at $S>75 \%$ (Table 3). Genotypes I-AB, I-BA (except for EM R. rutilus), and I$\mathrm{BC}$ (not detected only in fish GI) were isolated from all analyzed environments. In the case of genetic lines II$\mathrm{A}$ and $\mathrm{B}$ and genotypes $\mathrm{I}-\mathrm{AA}$ and $\mathrm{BB}$, the isolates 
Table 1 Total count of yeasts isolated from fish and sampling water

\begin{tabular}{llllll}
\hline Samples & Origin & $\begin{array}{l}\text { Number of fish } \\
\text { or water tested }\end{array}$ & $\begin{array}{l}\text { Spring } \\
\text { Log cfu g }{ }^{-1} \cdot 100 \mathrm{~mL}^{-1 *}\end{array}$ & Summer & Autumn \\
\hline Water & EO & 30 & $1.93( \pm 2.01)$ & $2.33( \pm 1.75)$ & $2.36( \pm 2.33)$ \\
Abramis brama & EM & 40 & $3.55( \pm 3.01)$ & $2.24( \pm 1.72)$ & $3.68( \pm 2.65)$ \\
& GI & & $2.78( \pm 2.29)$ & $2.83( \pm 2.21)$ & $2.94( \pm 2.43)$ \\
Rutilus rutilus & EM & 40 & $4.43( \pm 4.27)$ & $2.27( \pm 1.79)$ & $4.45( \pm 3.25)$ \\
& GI & & $2.44( \pm 2.28)$ & $2.61( \pm 2.47)$ & $2.66( \pm 1.77)$ \\
Perca fluviatilis & EM & 40 & $4.23( \pm 3.95)$ & $2.63( \pm 2.24)$ & $4.51( \pm 3.96)$ \\
& GI & & $2.49( \pm 2.01)$ & $2.92( \pm 1.75)$ & $2.57( \pm 2.33)$ \\
\hline
\end{tabular}

Results are means \pm SD

$E M$ epidermal mucus, GI gastric intestinal

*Samples of water

originated exclusively from the aquatic environment. The most diverse profile of the obtained RAPD patterns was noted for the group III-A and B (Fig. 3). The grouped strains were isolated exclusively from GI. Strains with genotypes III-AB and AC were found only in bream, whereas these with genotype III-AA

Table 2 Occurrences of yeasts (\%) in samples from fish

\begin{tabular}{|c|c|c|c|c|c|c|c|c|c|c|c|c|c|c|}
\hline \multirow[t]{2}{*}{ Species } & \multirow[t]{2}{*}{ Water } & & \multicolumn{4}{|c|}{ Abramis brama } & \multicolumn{4}{|c|}{ Rutilus rutilus } & \multicolumn{4}{|c|}{ Perca fluviatilis } \\
\hline & & & $\mathrm{EM}$ & & GI & & EM & & GI & & EM & & GI & \\
\hline C. albicans & 1.5 & op & 0.0 & - & 0.0 & - & 0.0 & - & 0.0 & - & 0.0 & - & 0.0 & - \\
\hline C. colliculosa & 0.2 & op & 4.0 & $\mathrm{ci}$ & 5.7 & op & 2.0 & ci & 8.0 & op & 1.3 & op & 0.0 & - \\
\hline C. famata & 5.6 & $\mathrm{ci}$ & 5.3 & $\mathrm{ci}$ & 9.7 & op & 11.6 & $\mathrm{ci}$ & 12.0 & op & 10.6 & $\mathrm{ci}$ & 4.3 & op \\
\hline C. guilliermondii & 0.6 & op & 1.1 & op & 6.3 & op & 3.9 & op & 3.7 & op & 3.6 & $\mathrm{ci}$ & 0.7 & op \\
\hline C. holmii & 1.1 & op & 0.3 & op & 5.0 & op & 1.3 & op & 2.3 & op & 0.6 & op & 0.0 & - \\
\hline C. lipolytica & 2.2 & $\mathrm{ci}$ & 0.0 & - & 0.0 & - & 1.0 & op & 6.0 & op & 0.0 & - & 0.0 & - \\
\hline C. melibiose & 0.5 & op & 0.7 & op & 0.0 & - & 2.6 & op & 0.0 & - & 1.3 & op & 0.0 & - \\
\hline C. membranifaciens & 1.8 & op & 0.0 & - & 0.0 & - & 1.2 & ci & 4.3 & op & 0.6 & $\mathrm{ci}$ & 0.7 & op \\
\hline C. sake & 2.5 & op & 2.7 & op & 0.0 & - & 4.0 & op & 2.3 & op & 2.0 & op & 0.0 & - \\
\hline C. tropicalis & 0.7 & op & 0.0 & - & 0.0 & - & 0.0 & - & 0.0 & - & 0.0 & - & 0.0 & - \\
\hline Cr. albidus & 5.6 & $\mathrm{ci}$ & 5.0 & $\mathrm{ci}$ & 0.0 & - & 0.0 & - & 5.0 & op & 0.0 & - & 0.0 & - \\
\hline Cr. humicolus & 1.0 & op & 0.7 & op & 0.0 & - & 0.0 & - & 0.0 & - & 0.0 & - & 0.0 & - \\
\hline Cr. laurenti & 6.0 & $\mathrm{ci}$ & 5.3 & $\mathrm{ci}$ & 6.0 & $\mathrm{ci}$ & 2.1 & op & 7.0 & op & 4.5 & op & 5.0 & op \\
\hline Cr. neoformans & 5.6 & op & 0.0 & - & 0.0 & - & 0.0 & - & 0.0 & - & 0.0 & - & 0.0 & - \\
\hline Cr. uniguttulatus & 10.3 & $\mathrm{ci}$ & 17.5 & $\mathrm{ci}$ & 12.3 & $\mathrm{ci}$ & 17.6 & ci & 7.0 & ci & 14.9 & $\mathrm{ci}$ & 7.0 & ci \\
\hline Kl. apiculata & 1.1 & op & 0.0 & - & 0.0 & - & 0.0 & - & 0.0 & - & 0.0 & - & 0.0 & - \\
\hline P. carsonii & 3.7 & $\mathrm{ci}$ & 10.3 & $\mathrm{ci}$ & 8.3 & op & 5.0 & $\mathrm{ci}$ & 6.7 & op & 16.7 & $\mathrm{ci}$ & 11.3 & ci \\
\hline Rh. glutinis & 18.3 & $\mathrm{ci}$ & 12.0 & ci & 9.0 & $\mathrm{ci}$ & 20.5 & ci & 5.0 & ci & 20.1 & $\mathrm{ci}$ & 15.8 & ci \\
\hline Rh. minuta & 5.0 & op & 6.0 & op & 5.3 & op & 2.9 & op & 6.0 & op & 1.6 & op & 8.2 & op \\
\hline Rh. mucilaginosa & 14.9 & $\mathrm{ci}$ & 19.5 & $\mathrm{ci}$ & 20.0 & $\mathrm{ci}$ & 23.1 & $\mathrm{ci}$ & 17.9 & $\mathrm{ci}$ & 19.5 & $\mathrm{ci}$ & 41.7 & ci \\
\hline S. cerevisiae & 11.1 & $\mathrm{ci}$ & 4.6 & $\mathrm{ci}$ & 7.7 & op & 1.6 & op & 6.8 & op & 1.6 & op & 0.3 & op \\
\hline Tr. mucoides & 0.4 & op & 4.0 & $\mathrm{ci}$ & 4.7 & op & 0.0 & - & 0.0 & - & 1.1 & op & 0.0 & - \\
\hline
\end{tabular}

$c i$ constantly insulated, $o p$ occasionally insulated 
Table 3 The occurrence of Rh. mucilaginosa genotypes

\begin{tabular}{|c|c|c|c|c|c|c|c|c|}
\hline \multicolumn{2}{|c|}{ Genetic line } & \multicolumn{7}{|c|}{ Genotype } \\
\hline \multirow[t]{3}{*}{$S<50 \%$} & \multirow[t]{3}{*}{$50.0 \%<S<75.0 \%$} & \multicolumn{7}{|c|}{$S>75.0 \%$} \\
\hline & & \multirow{2}{*}{$\begin{array}{l}\text { Water } \\
\text { EO }\end{array}$} & \multicolumn{2}{|c|}{ Abramis brama } & \multicolumn{2}{|c|}{ Rutilus rutilus } & \multicolumn{2}{|c|}{ Perca fluviatilis } \\
\hline & & & EM & GI & EM & GI & EM & GI \\
\hline \multirow[t]{5}{*}{ I } & A & $\mathrm{AA}$ & - & - & - & - & - & - \\
\hline & & $\mathrm{AB}$ & $\mathrm{AB}$ & $\mathrm{AB}$ & $\mathrm{AB}$ & $\mathrm{AB}$ & $\mathrm{AB}$ & $\mathrm{AB}$ \\
\hline & $\mathrm{B}$ & $\mathrm{BA}$ & $\mathrm{BA}$ & $\mathrm{BA}$ & - & $\mathrm{BA}$ & $\mathrm{BA}$ & $\mathrm{BA}$ \\
\hline & & $\mathrm{BB}$ & - & - & - & - & - & - \\
\hline & & $\mathrm{BC}$ & $\mathrm{BC}$ & - & $\mathrm{BC}$ & - & $\mathrm{BC}$ & - \\
\hline \multirow[t]{4}{*}{ II } & A & $\mathrm{AA}$ & - & - & - & - & - & - \\
\hline & & $\mathrm{AB}$ & - & - & - & - & - & - \\
\hline & $\mathrm{B}$ & BA & - & - & - & - & - & - \\
\hline & & $\mathrm{BB}$ & - & - & - & - & - & - \\
\hline \multirow[t]{4}{*}{ III } & A & - & - & - & - & & - & $\mathrm{AA}$ \\
\hline & & - & - & $\mathrm{AB}$ & - & $\mathrm{AB}$ & - & - \\
\hline & & - & - & $\mathrm{AC}$ & & - & - & - \\
\hline & $\mathrm{B}$ & - & & $\mathrm{BA}$ & - & - & - & - \\
\hline
\end{tabular}

were isolated only from perch. There was no $R h$. mucilaginosa genotype that would be typical only of roach (Table 3).

Microbial adherence For further analyses, we used only isolates typical of GI, i.e., strains of Rh. mucilaginosa with genotypes III: $\mathrm{AB}, \mathrm{AC}, \mathrm{BC}$, and $\mathrm{AA}$. Adherence kinetics and biofilm formation were determined via colorimetric determination of XTT reduction, as an indicator of the metabolic activity of cells. The strains isolated from fish GI were found capable of biofilm formation, except for the genotype III-BA. In the other cases, cell density increased with time and reached plateau after 6-12 h (Fig. 1). The progress in cells adherence was correlated with the genetic profile of strains, which was confirmed in the statistical analysis $(p<0.05)$. There was no significant correlation between strain behavior and fish species.

EPS production kinetics Results of the statistical analysis demonstrated significant differences in biomass yield and EPS concentration produced in cultures of $A b \mathrm{III}-$ AC genotype strains $(2.73 \mathrm{~g} / \mathrm{L}$ and $0.25 \mathrm{~g} / \mathrm{L}$, respectively). In the remaining cultures, the respective values were comparable and fitted within the following ranges: $1.01-0.91 \mathrm{~g} / \mathrm{L}$ and $0.14-0.15 \mathrm{~g} / \mathrm{L}$. In addition, no significant differences were determined in the production of the analyzed polymers between strains of the distinguished genotypes. Their concentration was proportional to biomass production. For this reason, we calculated the specific production coefficient $\left(Y_{p / x}\right)$ which is indicative of the real EPS productivity by $1 \mathrm{~g}$ of biomass. The mean $Y_{p / x}$ value ranged from 0.14 to 0.15 in the case of the strains with genotypes III-AB, $\mathrm{AA}$, and $\mathrm{AC}$ and was almost twofold higher than the coefficient calculated for the strains with III-AC genotype, i.e., 0.09 (Fig. 2).

Biosynthesis of carotenoids by $R h$. mucilaginosa Spectrophotometric multi-component analysis was used to quantitate carotenoids synthesized by $R h$. mucilaginosa strains. Results of absorbance measurements demonstrated a correlation between strain genotype and their capability for pigments biosynthesis. Significant deviations noted in the values obtained for individual strains with the distinguished genotypes reflected also the strain-specific character of this capability. The highest carotenoid-producing capability was determined for strains with the A. brama IIIAB genotype, whereas the lowest ones for these with the A. brama III-BA genotype (Table 4). Results of absorbance measurements point to the presence of a 


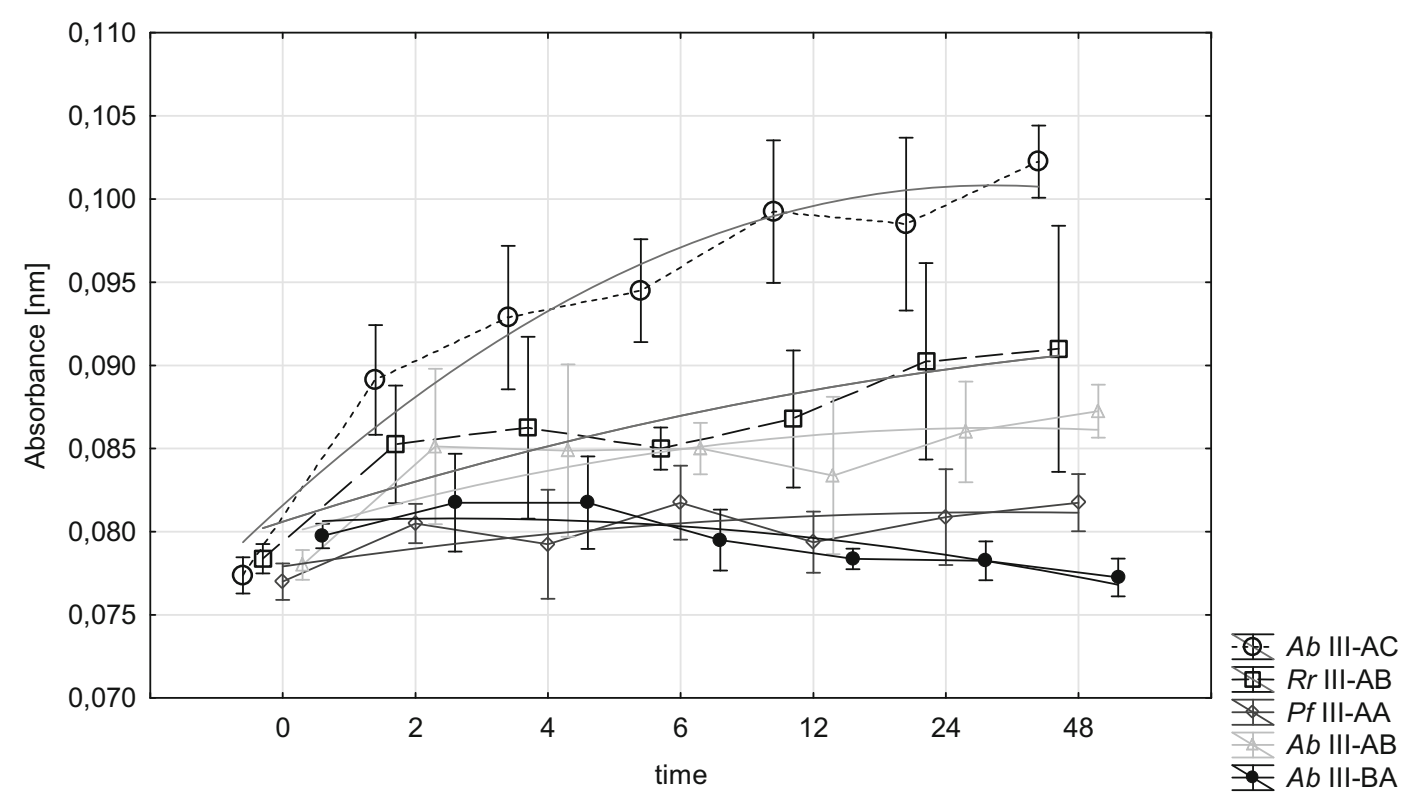

Fig. 1 Adhesion of the yeast genotype

combination of three pigments- $\beta$-carotene, torularhodin, and torulene (Table 4). All analyzed strains produced a similar quantity of $\beta$-carotene. The content of torularhodin fraction in the total carotenoid content ranged from $25 \%$ for strains with A. brama III-BA genotype to $48.9 \%$ for these with $P$. fluviatilis III-AA genotype, whereas that of torulene reached $22.7 \%$ for R. rutilus III-AB strains and $46.5 \%$ for A. brama $\mathrm{III}-$ BA strains (Table 4).

\section{Discussion}

Fish colonization by yeast may have a significant impact on changes in relations between the host and the developing microbiota (Ringo et al. 2003). The first and key element of colonization control is the epidermal mucus. Its immunoglobulins, lectins, lysozyme, antimicrobial polypeptides, and compounds of various polarities regulate processes of biocontrol targeted mainly at

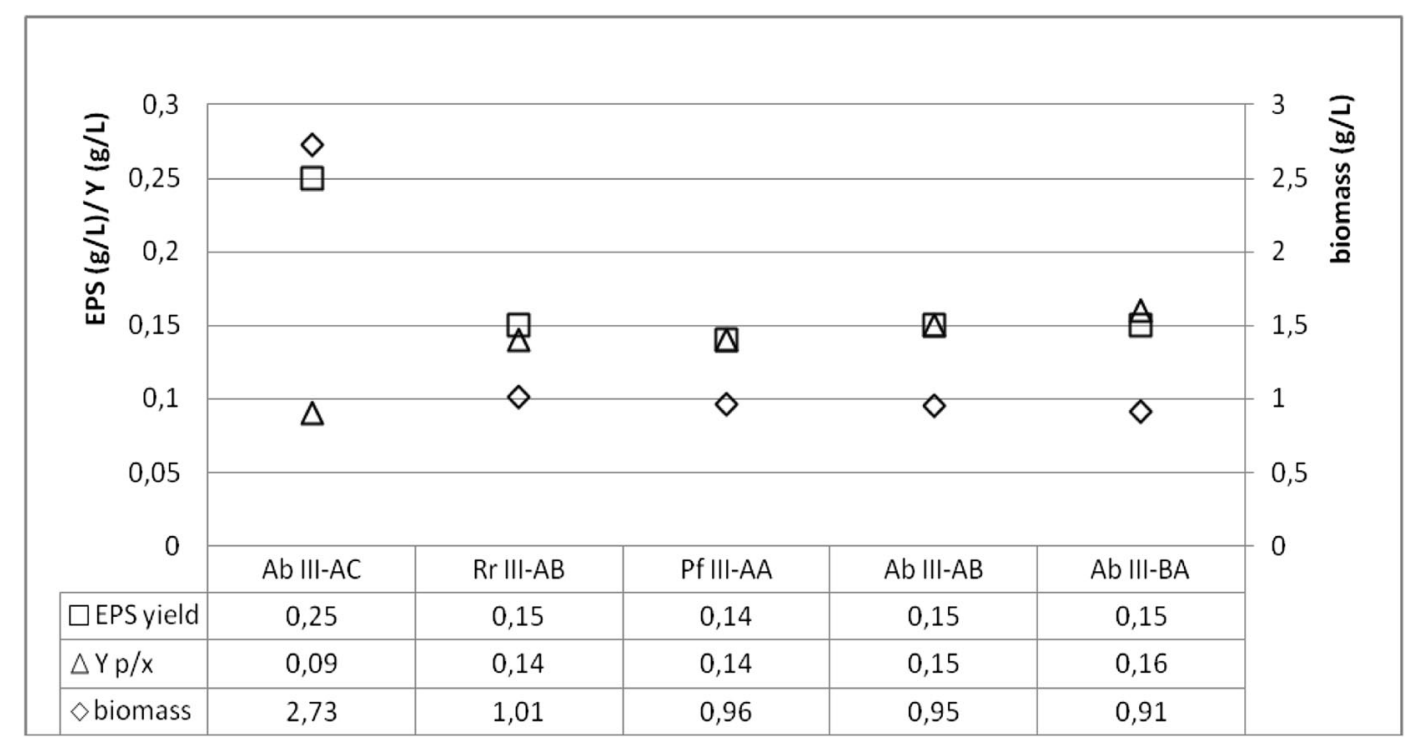

Fig. 2 EPS production as a function of cellular growth 
Table 4 Carotenoids produced of $R$ h. mucilaginosa

\begin{tabular}{|c|c|c|c|c|c|}
\hline \multirow[t]{2}{*}{ Carotenoid production } & \multicolumn{5}{|l|}{ Genotype } \\
\hline & A. brama $\mathrm{III}-\mathrm{AC}$ & R. rutilus $\mathrm{III}-\mathrm{AB}$ & P. fluviatilis $\mathrm{III}-\mathrm{AA}$ & A. brama $\mathrm{III}-\mathrm{AB}$ & A. brama $\mathrm{III}-\mathrm{BA}$ \\
\hline Total carotenoid content $\left(\mu \mathrm{g} \mathrm{g}^{-1}\right)$ & $159.4( \pm 46.963)$ & $183.8( \pm 53.418)$ & $149.1( \pm 66.184)$ & $226.83( \pm 53.195)$ & $131.2( \pm 41.033)$ \\
\hline \multicolumn{6}{|l|}{ Pigment composition (\%) } \\
\hline$\beta$-Carotene & 27.9 & 30.3 & 27.1 & 27.0 & 28.5 \\
\hline Torulene & 38.4 & 47.0 & 48.9 & 36.8 & 25.0 \\
\hline Torularhodin & 33.7 & 22.7 & 24.0 & 36.2 & 46.5 \\
\hline
\end{tabular}

Results are means $\pm \mathrm{SD}$

pathogenic bacteria. The development of pathogenic microflora is often accompanied by the effect of superinfection with yeast-like fungi (Tartor et al. 2018). Even a minimal amount of lysozyme can inhibit the reproduction of some yeast. Such mechanisms are believed to stem from ultrastructural and morphological changes of budding forms (Lopera et al. 2008). The effect of seasonal variability of yeast number in mucus is, thus, correlated with the physiological condition of a fish and its response to changes in environmental conditions. In the winter-spring period (December-April), a significant decrease is observed in the content of, e.g., hydrolytic protein, which is the direct reason behind increased counts of determined fungi (Table 1), and an increase in ATPases content in the epidermal layers of fish mucus (Schrock et al. 2001). It is the only justification of mycocenotic relations observed in our study between water and epidermal mucus. Comparable numbers of yeast in water samples are collected in all studied seasons ( $\log 1.93-2.36)$, and their seasonal variations in EM (spring $\log 3.55-4.43$ and autumn $\log 3.68-4.51$ ) were not correlated with GI mycocenoses of the investigated fish ( $\log 2.44-2.94)$. It was concluded that results of the qualitative and quantitative differentiation of yeast cannot be due only to their passive ingestion with feed. The analyzed fish species (bream, roach, perch) were characterized by a common feeding area-soft bottom and meadows of seagrass - and by diverse feed preferences (Elliott and Hemingway 2002). For this reason, we speculated that some of the yeasts could be natural symbionts.

When investigating the biological function of yeast in fish physiology, an overriding stage is to identify species claimed to be permanent residents. Of the 23 species isolated from water and fish samples, only three, Cr. uniguttulatus, Rh. glutinis, and Rh. mucilaginosa, appeared to be isolated permanently, with $R h$. mucilaginosa having the greatest contribution in the mycocenotic structure. Of the isolated Rhodotorula strains, we selected these with genetic profiles typical only of the gastrointestinal tract of fish. Selected at the level of $S<50 \%$, as strains non-affiliated with representatives of Rh. mucilaginosa isolated from water and mucus, they constituted a separate genetic group. Their intragroup affinity, determined at $S>75 \%$, allowed us to conclude that they represent an integral part of the microbiota of fish GI. Considering the above, we hypothesized about the capability of Rhodotorula spp. for permanent colonization of the gastrointestinal tract. Qualitative and quantitative differences in the microbiocenosis are determined by microbiological colonization at the early stage of fish development as well as by environmental conditions and changes in fish diet (Ringo et al. 2006; Olafsen 2001; Caruffo et al. 2015). The survival strategy of microorganisms is based on their adherence to GI mucus and using its components as sources of nutrients and energy. This explains typing strains of Rh. mucilaginosa at the probability level of $S>75 \%$ and their permanent residence in the GI. Among the four distinguished genotypes of $R h$. mucilaginosa, only the strains grouped in the BA genotype did not show the capability to adhere to GI mucus (Fig. 1), despite comparable rate of biomass formation and production of EPS as a biofilm stabilizer (Fig. 2). The kinetics of biofilm formation was the highest in the case of the AC genotype strains (Fig. 1). Worthy of notice, however, is the fact that this resulted from the rate of cell reproduction and not from the traits being indicative of the outstanding productivity of extracellular compounds (Fig. 2).

In the fish-yeast symbiotic regulation, the specific adherence of yeast is also aided by the presence of 
glycoprotein mucins secreted mainly by the epithelial cells of the gastrointestinal tract. They are composed of a high number of serine residues whose presence affects the process of fungi adherence. The colonization of GI by Rhodotorula spp., supported by the natural mechanisms of fish, alters the environment surrounding them. Metabolites produced by yeast modify physicochemical properties of the environment, and together with it, they induce processes of microbiological control. Synergistic dependencies between the surface of their cell wall and the epithelium are stabilized by extracellular compounds (EPS) synthesized by Rhodotorula. Overproduction of these polymers, as a consequence of activated defense mechanisms, reflects responses induced by the cellular stress. These responses are not limited only to interactions with EPS producers (yeast cells) but are becoming a protective barrier for GI ichthyofauna by being a matrix for an epibiotic biofilm development (Boguslawska-Was 2010). One of the biological functions of EPS is their capability to inhibit the growth of bacteria and to, simultaneously, suppress lysozyme activity towards yeast. This presumption was confirmed by results of our study (Fig. 2). The fact of extracellular biopolymers formation should be interpreted in connection with the possibility of controlled cellular reproduction of Rhodotorula. Parameters of specific productivity $\left(Y_{p / x}\right)$ computed for all analyzed genotypes show explicitly that EPS biosynthesis is a strain-specific trait. A lack of a strict correlation between the biomass formation and biosynthesis of extracellular compounds may suggest the existence of control mechanisms which reduce yeast prevalence in GI. EPS which are polysaccharides constitute a very good source of nutrients (ChapotChartier 2014; Hou et al. 2013; Molina et al. 2012). Their composition is claimed to be responsible for prebiotic properties (Navarrete and Tovar-Ramírez 2014) and for the stimulation of glucan activity in processes of immunostimulation (Tovar-Ramírez et al. 2010).

The symbiotic role of Rh. mucilaginosa includes also its natural capability to synthesize carotenoids (Fig. 3). Results obtained in our study indicated no correlation between the genotype and amount of accumulated pigments. This trait was found to be strain-dependent (Table 2). In yeast cells, the carotenoids play primarily the function of membrane-protective antioxidants. However, their participation in the mechanisms of response to exogenous stress factors points to their significantly wider biological activity. Physiological demand for molecules of this type is not permanent but reflects cell adaptation to environmental changes (Cheng and Yang 2016; Marova et al. 2011). This concerns also fish which are incapable of endogenous synthesis of these pigments. It is of special significance for immune system activation processes, including activation of mechanisms controlled by non-specific protection systems. The permanent presence of Rh. mucilaginosa in the gastrointestinal tract may provide a source of valuable compounds used to counteract effects of oxidative stress. Its most often causes include stress and progressing infections (viral, bacterial, or parasitic). In response to threat, the immune system is stimulated and reactive oxygen and nitrogen species (ROS and RNS) are activated as molecules aiding defense mechanisms. Extreme situations may evoke overproduction of these pro-oxidants, which leads to permanent changes in host cells (Splettstoesser and Schuff-Werner 2002). According to Costantini, the effect of autodestructive changes is also ascribed to the excessive expression of stress hormones - corticosteroids, induced by outcomes of intense oxidative stress (Costantini et al. 2008). Likewise in the silencing of the excessive response of the immune system, also in the case of hormonal regulation, significant role will be ascribed to the mechanisms of release of compounds compensating for deficiencies of endogenous antioxidants. The active cells of Rhodotorula coforming the commensal microbiota or accumulated products of their biosynthesis enable activation of the carotenoid system. The initiation of mechanisms enabling the release of non-enzymatic molecules that capture free radicals and cytotoxic molecules (Chew and Park 2004) contributes to the alleviation of the outcomes of the oxidative stress. Biosynthesis and circulation control of carotenoids or their derivatives used by fish (Mougeot et al. 2010) are due to the response to the host's needs (Marova et al. 2010; Sefc et al. 2014). Results of our experiment clearly indicate that all analyzed strains, found to be the natural epibiota of the gastrointestinal tract, were producers of $\beta$-carotene, torulene, and torularhodin fractions typical of $R h$. mucilaginosa (Table 2). It is difficult to establish which of them is more significant to fish, because the antioxidative effect of carotenoids is believed to result from the so-called overlapping activities of individual fractions. However, considering the range of the biological functions, the key role is ascribed to $\beta$-carotene (Mannazzu et al. 2015). Its production was determined at a similar level for all strains isolated from GI of the analyzed fish. However, torularhodin is much more 
Fig. 3 Examples for the RAPDPCR of Rh. mucilaginosa isolated from GI of fish

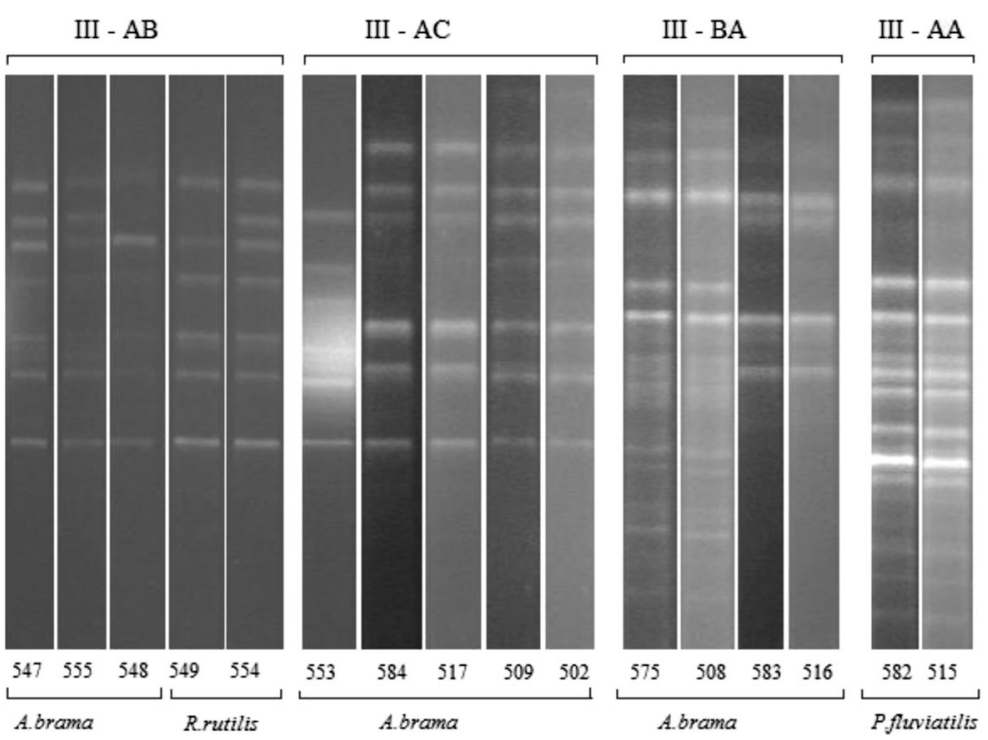

efficient than $\beta$-carotene in protecting cells against toxic action of singlet oxygen (Sakaki et al. 2001). Determination of torularhodin and torulene contents demonstrated their varying contributions in total carotenoids. Known as vitamin A precursors and singlet oxygen radical scavengers, they are regulated by environmental factors (El-Banna et al. 2012).

Carotenoids are the main elements of the arsenal of antioxidants in animals. However, the role of Rhodotorula in the gastrointestinal tract should not be limited only to their natural source. Many investigations have also confirmed carotenoids involvement in the immunostimulating processes through enhanced activation of T lymphocytes, through supporting the action of macrophages (Pérez-Rodríguez 2009), or through the antimicrobial activity. Already at the end of 1990s, Calvente has formulated a thesis that siderophores secreted by $R h$. glutinis play a significant role in processes of iron-dependent mycotic virulence (Calvente et al. 2001). Inhibition of microorganism development through the formation of ferric complexes with rhodotorulic acid of yeast results from the competition of siderophores with iron whose availability is a key element in host-bacterial flora interactions.

Yeast predispositions for colonizing, most of all, the gastrointestinal tract of fish seem obvious. The optimal $\mathrm{pH}$ for their growth (Martinem et al. 2006), tolerance to selective factors, and natural traits of selected Rhodotorula strains contribute to their classification as an element of naturally developing microbiota of fish. The biological activity of these fungi is exploited not only as a result of direct relations with the higher organism they colonize. Consortium relations between microorganisms become an element of the protective system against pathogenic microorganisms (bacteria and viruses). As a result of all these processes, the wild fish can compensate for deficits caused by fluctuations in their defense mechanisms and their response to environmental stress.

Authors' Contributions E.B-W-concept idea and implementation and date analysis; A.D., M.L.- preparation of manuscript.

Open Access This article is distributed under the terms of the Creative Commons Attribution 4.0 International License (http:// creativecommons.org/licenses/by/4.0/), which permits unrestricted use, distribution, and reproduction in any medium, provided you give appropriate credit to the original author(s) and the source, provide a link to the Creative Commons license, and indicate if changes were made.

\section{References}

Antachopoulos C, Meletiadis J, Roilides E, Sein T, Walsh T (2006) Rapid susceptibility testing of medically important zygomycetes by XTT assay. J Clin Microbiol 44(2):553-560

Balcazar JL, Venderell D, De Bas I, Girones O (2008) Characterization of probiotic properties of lactic acid bacteria isolated from intestinal microbiota. J Fish Aquac 278(1-4): 188-191

Bogusławska-Was E (2010) The diversity of yeast community in the Odra estuary and their influence on the development of ichthyofauna. Dissertation West Pomeranian University of Technology ISBN 978-7663*071-7 
Calvente V, Orellano ME, De Sansone G, Benuzzi D, Tosetti MIS (2001) A simple agar plate assay for screening siderophore producer yeasts. J Microbiol Methods 47:273-279

Caruffo M, Navarrete N, Salgado O, Díaz A, López P, García K, Feijóo CG, Navarrete P (2015) Potential probiotic yeasts isolated from the fish gut protect zebrafish (Danio rerio) from a Vibrio anguillarum challenge. Front Microbiol 6 . https://doi.org/10.3389/fmicb.2015.01093

Chapot-Chartier MP (2014) Interactions of the cell-wall glycopolymers of lactic acid bacteria with their bacteriophages. Front Microbiol 5. https://doi.org/10.3389 /fmicb.2014.00236

Cheng YT, Yang CF (2016) Using strain Rhodotorula mucilaginosa to produce carotenoids using food waste. $\mathrm{J}$ Taiwan Inst Chem E 61:270-275

Chew BP, Park JS (2004) Carotenoid action on the immune response. J Nutr 134:257-261

Costantini D, Fanfan A, Dell'Omo G (2008) Effect of carotenoids and oxidative damage and circulating carotenoids in captive adult kestrels (Falco tinnunculus). J Comp Physiol B 178: 829-835

El-Banna A, El-Razek AM, El-Mahdy AR (2012) Some factors affecting the production of carotenoids by Rhodotorula glutinis var. glutinis. Food NutrSci 3:64-71

Elliott M, Hemingway KL (2002) Fishes in estuaries. Blackwell, Oxford

Ghada SI, Manal GM, Asker M, Eman AG (2012) Production and biological evaluation of exopolysaccharide from isolated Rhodotorula glutinins. Aust J Basic Appl Sci 6(3):401-408

Gopalakannan A, Arul V (2010) Enhancement of the innate immune system and disease-resistant activity in Cyprinus carpio by oral administration of $\beta$-glucan and whole cell yeast. Aquac Res 41(6):884-892

Hatoum R, Labrie S, Fliss I (2012) Antimicrobial and probiotic properties of yeasts from fundamental to novel applications. Front Microbiol 3:421

He S, Wan Q, Ren P, Yang Y, Yao F, Zhou Z (2011) The effect of dietary Saccharoculture on growth performance, non-specific immunity and autochthonous gut microbiota of gibel Carp Carassius auratus. J Aquac Res Dev s1. https://doi. org/10.4172/2155-9546.S1-010

Hou W, Ma Z, Sun L, Han M, Lu J, Li Z, Abdalla O, Wei G (2013) Extracellular polymeric substances from copper-tolerance Sinorhizobium meliloti immobilize $\mathrm{Cu}^{2}+$. J Hazard Mater 261:614-620

Irianto A, Austin B (2002) Probiotics in aquaculture. J Fish Dis 25: 633-642

Jin L, Szeto KY, Zhang L, Du W, Sun H (2004) Inhibition of alcohol dehydrogenase by bismuth. J Inorg Biochem 98(8): 1331-7

Lokesh J, Fernandes J, Korsnes K, Bergh O, Brinchmann M, Kiron V (2012) Transcriptional regulation of cytokines in the intestine of Atlantic cod fed yeast derived mannan oligosaccharide or beta-glucan and challenged with Vibrio anguillarum. Fish Shellfish Immunol 33:626-631

Lopera D, Aristizabal BH, Restrepo A, Cano LE, González A (2008) Lysozyme plays a dual role against the dimorphic fungus Paracoccidioides brasiliensis. J Trop Med 50(3): 169-175

Maldonade IR, Rodriguez-Amaya DB, Scamparini ARP (2012) Statistical optimisation of cell growth and carotenoid production by Rhodotorula mucilaginosa. Braz J Microbiol 43:109-115

Mannazzu I, Landolfo S, Lopes de Silva T, Buzzin P (2015) Red yeasts and carotenoid production: outlining a future for nonconventional yeasts of biotechnological interest. World J Microb Biot 31:1665-1673

Marova I, Carnecka M, Halienova A, Koci R, Breierova E (2010) Production of carotenoid/ergosterol supplemented biomass by red yeast Rhodotorula glutinis grown under external stress. Food Technol Biotechnol 48:56-61

Marova I, Certik M, Breierova E (2011) Production of enriched biomass by carotenogenic yeasts - application of whole-cell yeast biomass to production of pigments and other lipid compounds, biomass - detection, production and usage. https://doi.org/10.5772/19235

Martinem C, Gertosio C, Labbe A, Perez R, Ganga MA (2006) Production of Rhodotorula glutinis: a yeast that secretes $\alpha$-Larabinofuranosidase. Electron J Biotechnol 9:407-413

Meena DK, Das P, Kumar S, Mandal SC, Prusty AK, Singh SK, Akhtar MS, Behera BK, Kumar K, Pal AK, Mukherjee SC (2013) Beta-glucan: an ideal immunostimulant in aquaculture. Fish Physiol Biochem 39:431-457

Molina IJ, Ruiz-Ruiz C, Quesada E, Bejar V (2012) Biomedical applications of exopolysaccharides produced by microorganisms isolated from extreme environments. In: Singh OV (red) Extremophiles: sustainable resources and biotechnological implications. https://doi.org/10.1002/9781118394144.ch14

Mougeot FJ, Martinez-Padilla JD, Blount L, Perez-Rodriguez LMI, Webster S, Piertney B (2010) Oxidative stress and the effect of parasites on a carotenoid-based ornament. J Exp Biol 213:400-407

Navarrete P, Tovar-Ramírez D, (2014) Use of yeasts as probiotics in fish aquaculture. In: Hernandez-Vergara M (ed) Sustainable aquaculture techniques. https://doi.org/10.5772 157196

Olafsen JA (2001) Interactions between fish larvae and bacteria in marine aquaculture. Aquaculture 200:223-247

Pavlova K, Panchev I, Hristozova T (2005) Physico-chemical characterization of exomannan from Rhodotorula acheniorum MC. World J Microb Biot 21:279-283

Pérez-Rodríguez L (2009) Carotenoids in evolutionary ecology: re-evaluating the antioxidant role. BioEssays 31(10):11161126

Ramage G, Vandewalle K, Wickes BL, JL L-R (2001) Characteristics of biofilm formation by Candida albicans. Rev Iberoam Micol 18:163-170

Ringo E, Olsen RE, Mayhew TM, Myklebust R (2003) Electron microscopy of the intestinal microflora of fish. Aquaculture 227:395-415

Ringo E, Sperstad S, Myklebust R, Refstie S, Krogdahl A (2006) Characterisation of the microbiota associated with intestine of Atlantic cod (Gadus morhua L.): the effect of fish meal, standard soybean meal and a bioprocessed soybean meal. Aquaculture 261:829-841

Sakaki H, Nakanishi T, Tada A, Miki W, Komemushi S (2001) Activation of torularhodin production by Rhodotorula glutinis using weak white light irradiation. J Biosci Bioeng 92:294-297

Schrock RM, Smith SD, Maule AG, Doulos SK, Rockowsk JJ (2001) Mucous lysozyme levels in hatchery coho salmon (Oncorhynchus kisutch) and spring chinook salmon 
(O. tshawytscha) early in the parr-smolt transformation. Aquaculture 198:169-177

Sefc KM, Brown AC, Clotfelter ED (2014) Carotenoid-based coloration in cichlid fishes. Comp Biochem Physiol A 173:42-51

Splettstoesser WD, Schuff-Werner F (2002) Oxidative stress in phagocytes - "the enemy within". Microsc Res Techniq 57(6):441-455

Stachowiak B (2012) Astaxanthin synthesis by yeast Xanthophyllomyces dendrorhous and its mutants on media based on plant extracts. Indian J Microbiol 52(4):654-659

Tartor Y, Tahaa M, Mahboubb H, Ghameryc ME (2018) Yeast species associated with diseased fish: occurrence, identification, experimental challenges and antifungal susceptibility testing. Aquaculture 48:134-144

Tovar-Ramírez D, Mazurais D, Gatesoupe F, Quazuguel P, Cahu C, Zambonino-Infante J (2010) Dietary probiotic live yeast modulates antioxidant enzyme activities and gene expression of sea bass (Dicentrarchus labrax) larvae. Aquaculture 300: $142-147$

White TJ, Burns T, Lee S, Taylor JW (1990) Amplification and direct sequencing of fungal ribosomal RNA genes for phylogenetics. In: Innis MA, Gelfand DH, Sninsky TJ, White TJ (eds) A guide to methods and applications. Academic Press, San Diego CA, pp 315-322 